\title{
Characterization and application of an avian in vitro spermatozoa-egg interaction assay using the inner perivitelline layer from laid chicken eggs
}

\author{
L. Robertson*, H. L. Brown, H. J. Staines and G. J. Wishart \\ Avian Reproduction Group, Division of Biological Sciences, School of Molecular and Life Sciences, \\ University of Abertay Dundee, Bell Street, Dundee DD1 1HG, UK
}

\begin{abstract}
The inner perivitelline layer, separated from laid chicken eggs, was investigated as readily available material for studying the spermatozoa-egg interaction in vitro. This layer was found to have a similar response to hydrolysis by spermatozoa as the inner perivitelline layer from ovulated and follicular ova, in terms of the numbers of points of hydrolysis made by spermatozoa during a $5 \mathrm{~min}$ incubation at $40^{\circ} \mathrm{C}$. Initiation of hydrolysis of the inner perivitelline layer was found to occur within $2.5 \mathrm{~min}$, after which the size, but not the number of holes, increased with time. The frequency of the points of hydrolysis per unit area of the inner perivitelline layer was positively correlated with the concentration of spermatozoa in the incubation medium. The perivitelline hydrolysis assay was able to detect more damaged spermatozoa in samples that had been either stored at $5^{\circ} \mathrm{C}$ or cryopreserved in liquid $\mathrm{N}_{2}$ than did other tests of sperm quality, which are known to overestimate the fertilizing ability of stored avian semen.
\end{abstract}

\section{Introduction}

The spermatozoa-egg (sperm-egg) interaction in birds is initiated by the binding of spermatozoa to the inner perivitelline layer, which is a proteinaceous layer surrounding the ovum (Bakst and Howarth, 1977). Once bound, the spermatozoa must hydrolyse a path through this layer to enter and fertilize the newly ovulated ovum (Okamura and Nishiyama, 1978). Unlike the sperm-egg interaction in mammals (Longo, 1987), there is no physiological block to polyspermy in avian species (see Perry, 1987). However, a further proteinaceous layer secreted by the oviduct, the outer perivitelline layer, which is laid down around the inner perivitelline layer shortly after fertilization, appears to inhibit any further hydrolysis of the inner perivitelline layer (Bakst and Howarth, 1977).

In vitro systems for studying the interaction of chicken spermatozoa with the inner perivitelline layer have been developed using fragments of inner perivitelline layer from ovulated ova (Koyanagi et al., 1988; Howarth, 1992) and ovarian follicles (Steele et al., 1994). These systems show that the inner perivitelline layer contains factors that act as sperm receptors, stimulate the acrosome reaction and subsequently enable the hydrolysis of a small hole in the inner perivitelline layer, through which spermatozoa penetrate the layer and reach the ovum. The number of spermatozoa penetrating the inner perivitelline layer can be determined by the number of points of hydrolysis (holes in the inner perivitelline layer) produced in a given time (Howarth, 1992; Bramwell and Howarth, 1992; Steele and Wishart, 1992).

*Correspondence.

Received 11 November 1996.
In mammals, in vitro assays for the interaction between spermatozoa and zonae pellucidae are valuable for studying the mechanisms involved in sperm binding and the initiation of the acrosome reaction, as well as for estimating the quality and thus, potentially, the fertilizing ability of spermatozoa (Gamzu et al., 1992). However, the equivalent assays for the interaction between spermatozoa and the inner perivitelline layer in avian species have not been well characterized; such assays involve killing the hen and are limited by the availability of material, since only one ovulated ovum and a limited number of follicles can be obtained per bird.

Kido and Doi (1988) showed that it was possible to separate the inner and outer perivitelline layers from laid chicken eggs by acid hydrolysis, to provide a large and readily obtainable quantity of material. The separated layers appeared to be structurally and chemically similar to those of the intact layer, although their functional status was not assessed. Steele $e t$ al. (1994) found that the electrophoretic mobilities of peptides from the inner perivitelline layer from laid eggs were different from those of this layer in ovulated eggs, and suggested that the addition of the outer perivitelline layer might induce conformational changes in proteins of the inner perivitelline layer and thus inhibit further binding and hydrolysis by spermatozoa.

In this study, we have investigated the response of the inner perivitelline layer separated from laid chicken eggs as a substrate for hydrolysis by spermatozoa in vitro. We have further characterized and applied this system as a quantitative assay of sperm function in which the end point of the assay is the frequency of points of hydrolysis produced in the inner perivitelline layer. 


\section{Materials and Methods}

\section{Maintenance of birds and semen collection}

Male chickens (Gallus domesticus) were from ISA 'Grandparent' cockerels (ISA Poultry Services, Peterborough) and chicken hens were ISA Brown commercial layers. All birds were caged individually under a photoperiod of $14 \mathrm{~h}$ light: $10 \mathrm{~h}$ dark and fed a commercial breeder's ration ad libitum. Semen was collected by abdominal massage (Burrows and Quinn, 1937) and ejaculates from three or four males were pooled to provide each sample.

\section{Preparation of inner perivitelline layer}

The inner perivitelline layer was obtained from ovulated, follicular and laid eggs. Newly ovulated ova were obtained from the body cavity or the first few centimetres of the infundibulum of hens killed by injection of $3 \mathrm{ml}$ Euthatal (RBM Animal Health Ltd, Dagenham) into the wing vein, approximately $15 \mathrm{~min}$ after oviposition. Free ova were suspended in $1 \%(\mathrm{w} / \mathrm{v}) \mathrm{NaCl}$ and cut equatorially until almost in two and the inner perivitelline layer was 'peeled' from the yolk. The layer was washed free of adherent yolk by several washes in $1 \%$ $(\mathrm{w} / \mathrm{v}) \mathrm{NaCl}$ and was finally resuspended in $0.15 \mathrm{~mol} \mathrm{NaCl} \mathrm{l^{-1 }}$ with $20 \mathrm{mmol}$ TES (N-Tris[hydroxymethyl]-methyl-2-aminoethanesulfonic acid) $\mathrm{l}^{-1}$ at $\mathrm{pH} 7.4(\mathrm{NaCl}-\mathrm{TES})$, and stored at $5^{\circ} \mathrm{C}$ for up to $24 \mathrm{~h}$ before use. Ovarian follicles were halved, washed in $1 \% \mathrm{NaCl}$ to remove the yolk and the inner perivitelline layer gently teased from the follicle wall using forceps. The inner perivitelline layer was washed, care being taken to remove all the granulosa cells, and stored as before.

The inner perivitelline layer was separated from the outer perivitelline layer of laid eggs by acid hydrolysis as described by Kido and Doi (1988). Essentially, egg yolks were isolated and washed free of albumin in $1 \% \mathrm{NaCl}$. Yolks were then immersed in $0.01 \mathrm{~mol} \mathrm{HCl}^{-1}$ and incubated at $37^{\circ} \mathrm{C}$ for $1 \mathrm{~h}$. After incubation, the $\mathrm{HCl}$ was removed and replaced by $1 \%$ $\mathrm{NaCl}$. The yolks were punctured with forceps and the perivitelline layer was washed several times in $1 \% \mathrm{NaCl}$ to remove yolk material. The perivitelline layer was then spread out in a Petri dish containing $1 \% \mathrm{NaCl}$ and the inner and outer layers were carefully pulled apart using forceps. The isolated inner perivitelline layer was stored at $5^{\circ} \mathrm{C}$ as for other samples.

\section{SDS-PAGE of perivitelline layer proteins}

Samples, $\mathrm{I} \mathrm{cm}^{2}$, of ovulated, follicular and inner, outer and whole perivitelline layer from laid eggs were solubilized by boiling them in a solution containing $5.5 \%(\mathrm{w} / \mathrm{v})$ SDS and $0.14 \%(\mathrm{v} / \mathrm{v}) \quad \beta$-mercaptoethanol for $5 \mathrm{~min}$. Solubilized samples were centrifuged at $13000 \mathrm{~g}$ for $5 \mathrm{~min}$ and $3.5 \mu \mathrm{l}$ aliquots of the supernatants were loaded on to $5-15 \%$ gradient gels $(12 \mathrm{~cm} \times 10 \mathrm{~cm})$, which were run on a Fisons FEC 185 Dual Mini Vertical Electrophoresis System at a constant current of $15 \mathrm{~mA}$ for $1.5 \mathrm{~h}$ at $5^{\circ} \mathrm{C}$ according to the method of Laemmli (1970). Molecular masses of the proteins were estimated using BDH 'Electran' molecular weight markers in the range $12-78 \mathrm{kDa}$. After separation, gels were fixed in water:methanol:acetic acid (4:5:I; v:v:v) and silver-stained according to the method described by Blum et al. (1987).

\section{Storage of chicken spermatozoa at low temperature}

Cryopreservation of spermatozoa was carried out using glycerol as the cryoprotectant, by the method described by Wishart (1995), after Lake and Stewart (1987). Samples were cooled from $5^{\circ} \mathrm{C}$ to $-35^{\circ} \mathrm{C}$ at a rate of $-3^{\circ} \mathrm{C}$ min ${ }^{-1}$ using a Kryo-10 programmable freezer (Planer Products Ltd, Sunbury). They were then transferred to liquid $\mathrm{N}_{2}$ and stored at $-196^{\circ} \mathrm{C}$ until required. Samples were thawed by immersion in liquid at $5^{\circ} \mathrm{C}$, diluted in ' 92 ' solution (see Wishart, 1995) at this temperature, centrifuged at $700 \mathrm{~g}$ for $15 \mathrm{~min}$ and subsequently resuspended in $\mathrm{NaCl}-\mathrm{TES}$ at a final concentration of $10^{9}$ spermatozoa $\mathrm{ml}^{-1}$.

For liquid storage at $5^{\circ} \mathrm{C}$, semen was diluted $1: 3$ in diluent '7.1' (Lake and Ravie, 1981) and $2 \mathrm{ml}$ samples, contained within $25 \mathrm{ml}$ Nalgene plastic conical flasks, were aerated by agitating them in a shaking water bath. Anaerobic conditions were maintained in similarly diluted samples held in sealed $0.5 \mathrm{ml}$ Eppendorf tubes. Both samples were stored for $24 \mathrm{~h}$.

\section{Sperm 'quality' assays}

The ability of spermatozoa to reduce the tetrazolium salt 2-[p-iodophenyl]-3-[p-nitrophenyl]-5-phenyltetrazolium chloride (INT) to a strongly coloured formazan was measured as described by Chaudhuri and Wishart (1988).

The morphology of spermatozoa was determined by examination of aniline-eosin smears as described by Haije (1990). A 1:30 dilution of spermatozoa: dye was prepared and incubated at $5^{\circ} \mathrm{C}$ for $2 \mathrm{~min}$. A volume of $20 \mu \mathrm{l}$ was then smeared on to a slide, dried immediately in a stream of cold air and examined under oil at $\times 1000$. The percentage of spermatozoa that showed normal morphology and was impermeable to eosin was calculated.

\section{Spermatozoa-perivitelline-layer interaction assay}

Fresh samples of pooled semen were diluted I:4 in NaClTES and stored aerobically at $30^{\circ} \mathrm{C}$ for up to $\mathrm{I} h$ before use. Samples stored at low temperatures were processed directly from $5^{\circ} \mathrm{C}$. In all spermatozoa-egg interaction assays, $0.5 \mathrm{~cm} \times 0.5 \mathrm{~cm}$ pieces of inner perivitelline layer were incubated with spermatozoa at $40^{\circ} \mathrm{C}$ in polycarbonate vials containing $1.0 \mathrm{ml}$ Dulbecco's modified Eagles' minimal essential medium, buffered with $10 \mathrm{mmol}$ Hepes $1^{-1}$ (GIBCO BRL, Life Technologies, Paisley). Standard assays used sperm concentrations of $1.25 \times 10^{7}$ spermatozoa $\mathrm{ml}^{-1}$ and a $5 \mathrm{~min}$ incubation (Steele et al., 1994), although these conditions were varied experimentally. After incubation, the pieces of inner perivitelline layer were removed, washed in $\mathrm{NaCl}-\mathrm{TES}$, spread on microscope slides and covered with a coverslip. They were then examined at $\times 100$ using darkground optics and the number of holes in the inner perivitelline layer were counted in videoprints of three fields of view, each of $0.55 \mathrm{~mm}^{2}$. Each experiment was carried out in triplicate, unless otherwise stated. 


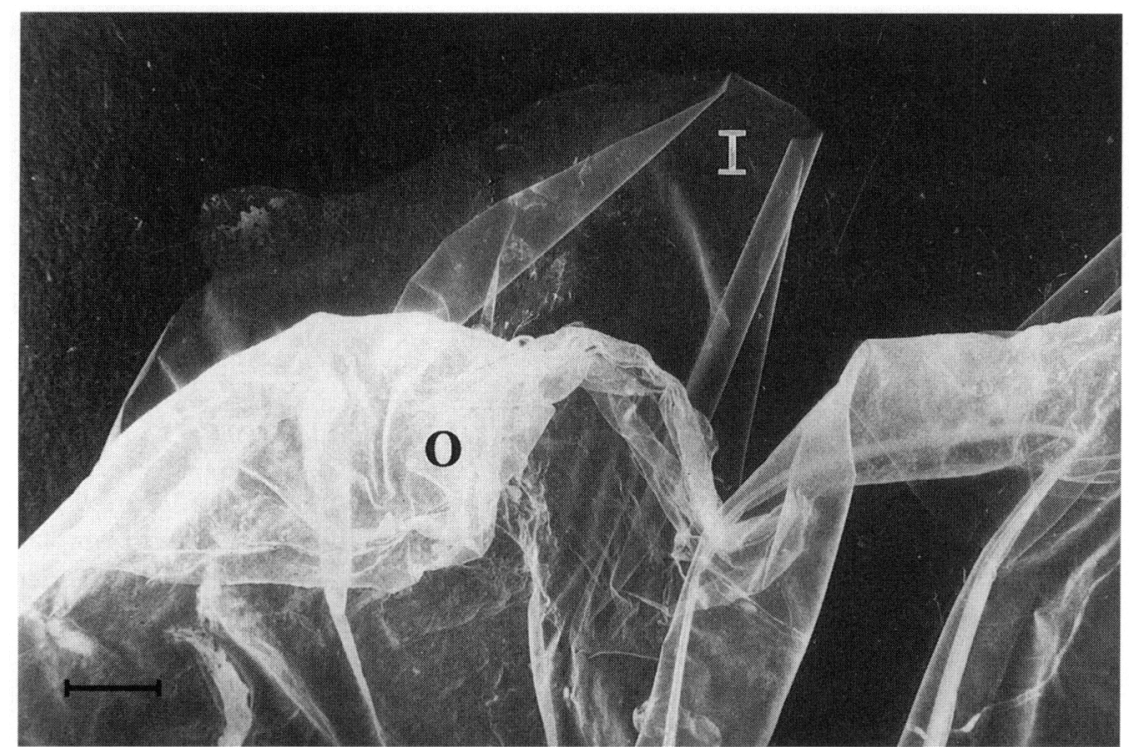

Fig. 1. Separation of inner and outer perivitelline layers from a laid chicken egg. The inner layer (I) can be distinguished from the outer $(\mathrm{O})$ layer as a thinner, more transparent structure. Scale bar represents $2 \mathrm{~mm}$.

\section{Statistical analyses}

Two-way nested analysis of variance (ANOVA) was used to test for differences among the mean number of points of hydrolysis for one factor controlling for different sources of experimental material; e.g. to show that the mean number of holes in the inner perivitelline layer did not vary among intra-egg samples, taking into account inter-egg differences. Analysis of covariance (ANCOVA) was used to test for a linear relationship of a variate with the mean number of points of hydrolysis controlling for different sources of experimental material; for example to establish the linear relationship between sperm concentration and the mean number of points of hydrolysis, while controlling for differences among the inner perivitelline layers. Before statistical analyses, the skewness of data was checked. The Kruskal-Wallis test was used as an alternative to ANOVA for particularly skewed data. For each statistical method used, standard diagnostic checks confirmed that the underlying assumptions were not violated (see Montgomery, 1991).

\section{Results}

\section{Characterization of perivitelline layers from laid eggs}

Acid treatment of the egg yolks resulted in the separation of the inner and outer perivitelline layers. The inner perivitelline layer could easily be distinguished in vitro as a thinner, more transparent structure (Fig. I). Kido and Doi (1988) found that eggs stored at $4^{\circ} \mathrm{C}$ for more than $24 \mathrm{~h}$ separated poorly. In contrast, we found that good separation of the layers could be obtained with eggs stored at room temperature for up to 3 days.

Figure 2 provides an example, typical of at least five similar experiments, of the peptide profiles obtained from the inner perivitelline layer of both ovulated and follicular eggs. These profiles appeared to be identical, with major bands at $78 \mathrm{kDa}$ and $39 \mathrm{kDa}$. A $78 \mathrm{kDa}$ band was also present in the inner and whole perivitelline layer from laid eggs but the $39 \mathrm{kDa}$ protein was absent and was replaced by a $35 \mathrm{kDa}$ band in these profiles (Fig. 2a, c). Neither of these bands were present in the outer perivitelline layer obtained from laid eggs (Fig. 2b).

\section{Characterization of the spermatozoa-egg interaction assay}

The mean frequency of holes in the inner perivitelline layer $\mathrm{mm}^{-2}$ of three replicates from three pieces of inner perivitelline layer taken from four eggs, each from different hens, were $253 \pm 53,135 \pm 30,513 \pm 50$ and $410 \pm 80$. A nested ANOVA showed no significant difference among the mean values within an egg $(F(8,2.3)=2.11 ; P>0.05)$ but significant differences were observed among eggs from different females $(F(3,23)=124.64 ; P<0.0005)$. Furthermore, when samples of inner perivitelline layer from the same egg were incubated with samples of spermatozoa from three different males, the Kruskal-Wallis test showed significant differences in the resultant median frequencies of 1104,364 and 129 holes in inner perivitelline layer $\mathrm{mm}^{-2}\left(\chi^{2}(2)=7.2 ; P<0.05\right)$.

The mean frequency of the holes in the inner perivitelline layer $\mathrm{mm}^{-2}$ in samples of inner perivitelline layer from ovulated, follicular and laid eggs, obtained from three hens and incubated for $5 \mathrm{~min}$ with the same sample of spermatozoa, were $373 \pm 106,420 \pm 104$ and $427 \pm 104$, respectively. A nested two-way ANOVA showed no significant differences $(F(2,18)=0.24 ; P>0.05)$ among the types of inner perivitelline layer for individual hens, but significant differences $(F(6,18)=$ 9.25; $P<0.0005$ ) were observed among hens.

Photomicrographs of samples of the inner perivitelline layer from the same egg, after exposure to increasing concentrations of spermatozoa from the same semen sample, are shown in 
a

b

c

d

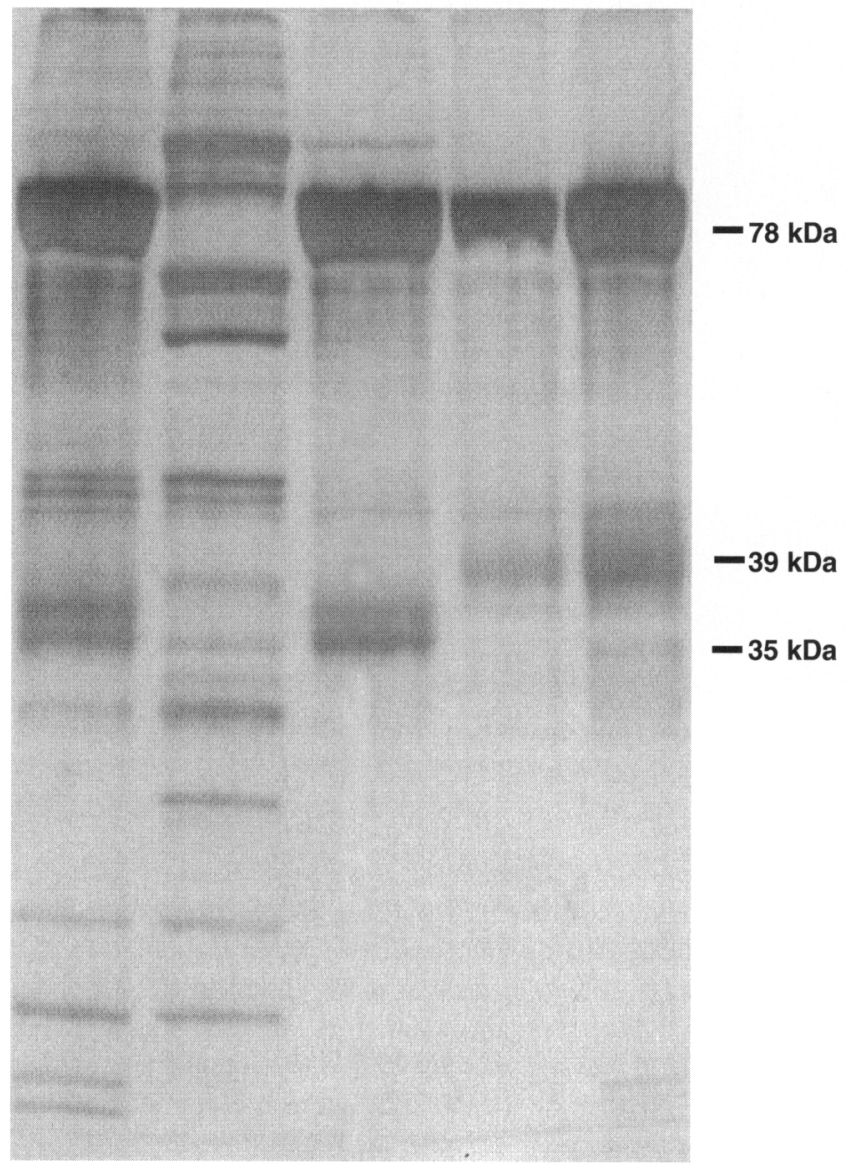

Fig. 2. SDS-PAGE peptide profiles of (a) the intact, (b) the outer and (c) the inner perivitelline layers from a laid chicken egg with inner layer from (d) a follicular and (e) an ovulated ovum. All samples were taken from the same bird.

Fig. 3. A graphical representation of results from a similar experiment using fragments of the inner perivitelline layer from the same egg is shown in Fig. 4. In four experiments using different spermatozoa and inner perivitelline layer samples from different eggs, an ANCOVA showed that there was a significant linear effect of the concentration of spermatozoa $(F(1,39)=152.85 ; P<0.01)$ after controlling for different semen and samples of the inner perivitelline layer $(F(3,39)=5.38$; $P<0.01$ ). Concentrations of spermatozoa greater than $62.5 \times 10^{7} \mathrm{ml}^{-1}$ caused the merging of holes or disintegration of the inner perivitelline layer.

Hydrolysis of the inner perivitelline layer by spermatozoa was first identified after incubation for $2.5 \mathrm{~min}$, at which time the holes were between $5 \mu \mathrm{m}$ and $10 \mu \mathrm{m}$ in diameter. After incubation for $5 \mathrm{~min}$, the diameter of the holes increased to 10-20 $\mu \mathrm{m}$. After incubation for $>10 \mathrm{~min}$ the average diameter of the holes in the inner perivitelline layer increased to $30-50 \mu \mathrm{m}$ and the holes started to merge, eventually resulting in the disintegration of the inner perivitelline layer.

Assays using the inner perivitelline layer from the same laid egg produced values of $112 \pm 59$ holes $\mathrm{mm}^{-2}$ after $2.5 \mathrm{~min}$, $100 \pm 28$ after $5 \mathrm{~min}$ and $76 \pm 29$ holes $\mathrm{mm}^{-2}$ after $10 \mathrm{~min}$ incubation.
In further experiments, a nested two-way ANOVA indicated significant differences among eggs from different hens $(F(2,18)=23.32 ; P<0.01)$ and among different sampling times $(F(2,18)=5.64 ; P=0.01)$. There was no significant difference between the mean number of holes in the inner perivitelline layer $\mathrm{mm}^{-2}$ at sampling times of 2.5 and $5 \mathrm{~min}(F(1,12)=0.31$; $P>0.05$ ), but the mean number of holes in the inner perivitelline layer $\mathrm{mm}^{-2}$ at $10 \mathrm{~min}$ was significantly lower than the number at 2.5 and $5.0 \mathrm{~min}(F(1,19)=11.25, P<0.01)$.

\section{Assay of stored spermatozoa}

These experiments were carried out using five replicates of the inner perivitelline layer from laid eggs only. Different concentrations of cryopreserved spermatozoa, produced by dilution of a single sample of cryopreserved semen, described a linear relationship with the frequency of hydrolysed holes in 30 different areas of inner perivitelline layer from the same egg (number of holes in the inner perivitelline layer $\mathrm{mm}^{-2}=-11+6 \times 10^{6}$ spermatozoa $\mathrm{ml}^{-1} ; r=0.87$ ). However, the ability of cryopreserved spermatozoa from different samples to hydrolyse the inner perivitelline layer was reduced to $9.4 \pm 0.5 \%$ of those from fresh, control samples $(n=5)$. Formazan production after cryopreservation was found to be reduced to $31.4 \pm 1.0 \%$ of that of fresh samples $(n=5)$.

Spermatozoa stored at $5^{\circ} \mathrm{C}$ for $24 \mathrm{~h}$ also showed an impaired ability to produce holes in the inner perivitelline layer. For samples from three different males, this was reduced to $52 \pm 7 \%$ of the value for fresh semen for aerobically stored and $5 \pm 3 \%$ for anaerobically stored samples. The ability of spermatozoa from the same samples to exclude eosin was reduced to $83 \pm 3 \%$ and $82 \pm 2 \%$ of the value for fresh semen and their ability to metabolize the tetrazolium salt INT was reduced to $90 \pm 7 \%$ and $92 \pm 8 \%$, for aerobically and anaerobically stored samples, respectively (see Fig. 5). There were no significant differences among males in the number of holes in the inner perivitelline layer, or in the ability of the spermatozoa to exclude eosin or reduce the tetrazolium salt INT (two-way ANOVA: $F(2,4)=1.20,2.73$ and 0.23 , respectively; $P>0.05$ for each test); however, spermatozoa from fresh samples performed better than those from stored samples (two-way ANOVA: $F(2,4)=99.8,80.8$ and 8.53 , respectively; $P<0.05$ for each test). Tukey's pairwise comparison showed no difference between aerobically and anaerobically stored spermatozoa in their ability to exclude eosin or reduce INT $(P>0.05$ for each test). In contrast, aerobically stored spermatozoa produced more holes in the inner perivitelline layer than did those stored anaerobically $(P<0.01)$.

\section{Discussion}

The inner perivitelline layer from ovulated, follicular and laid eggs displayed a similar ability to bind spermatozoa, initiate the acrosome reaction and promote the formation of a point of hydrolysis. Steele et al. (1994) showed that the inner perivitelline layer from ovarian follicles and from freshly ovulated ova is equally responsive to hydrolysis by spermatozoa. However, the likelihood that the inner perivitelline layer from laid eggs would also show a similar response to sperm hydrolysis could 

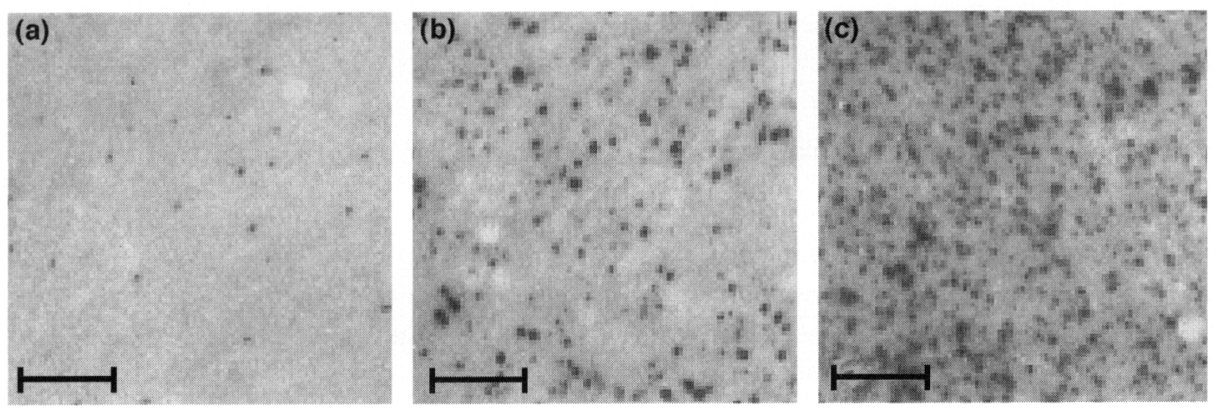

Fig. 3. Points of hydrolysis (holes in the inner perivitelline layer) present as dark 'holes' in the inner perivitelline layer of chicken eggs after incubation with increasing concentrations of spermatozoa; (a) $5 \times 10^{6}$ spermatozoa ml ${ }^{-1}$; (b) $25 \times 10^{6}$ spermatozoa $\mathrm{ml}^{-1}$; (c) $50 \times 10^{6}$ spermatozoa $\mathrm{ml}^{-1}$. Scale bars represent $150 \mu \mathrm{m}$.
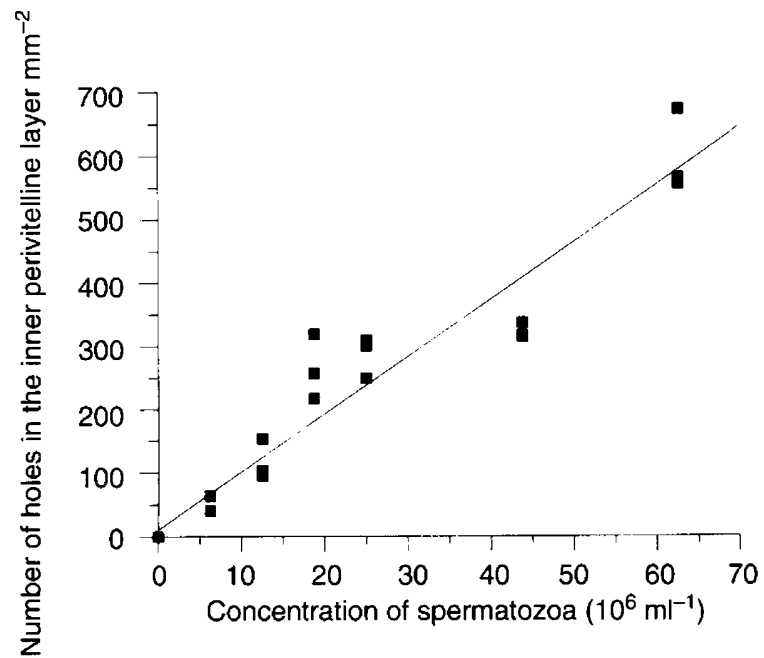

Fig. 4. Relationship between the concentration of spermatozoa and the number of holes in the inner perivitelline layer from laid chicken eggs in vitro. The relationship is holes $\mathrm{mm}^{-2}$ in the inner perivitelline layer $=10.9+9.08 \times 10^{6}$ spermatozoa ml $\mathrm{ml}^{-1} ; r=0.97$.

not have been predicted from earlier studies. Kido and Doi (1988) separated the inner from the outer perivitelline layer of laid eggs by acid hydrolysis and demonstrated that it retained some structural integrity, but no detail was available on its functional status; Steele et al. (1994) suggested that the addition of the outer perivitelline layer may alter the sperm-binding function of the inner perivitelline layer. Our studies show that neither the acid hydrolysis nor the laying down of the outer perivitelline layer appeared to affect the activity of the receptor.

The peptide profiles of the inner perivitelline layer obtained from follicular, ovulated and laid eggs were similar to each other and to those obtained by Steele et al. (1994). The $78 \mathrm{kDa}$ and the $39 \mathrm{kDa}$ peptides were present in the inner perivitelline layer from all three sources although, in the inner perivitelline layer from laid egg, the $39 \mathrm{kDa}$ band showed greater mobility at $35 \mathrm{kDa}$. This shift cannot be the result of acid hydrolysis since this also occurred in the whole perivitelline layer, which had not been subjected to this treatment. Steele et al. (1994) suggested that this change may be the result of postovulatory changes in the structure of the layer, or a change induced by

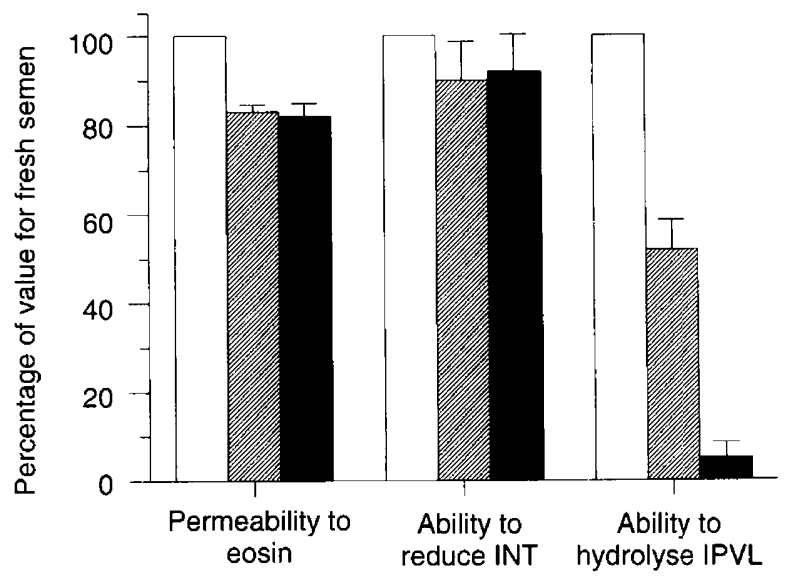

Fig. 5. Effect of storage of chicken semen at $5^{\circ} \mathrm{C}$ for $24 \mathrm{~h}$ on sperm eosin permeability, capacity of spermatozoa to reduce the tetrazolium salt (2-[p-iodophenyl]-3-[p-nitrophenyl]-5-phenyltetrazolium chloride; INT) and their ability to produce points of hydrolysis in the inner perivitelline layer (IPVL) of the chicken egg. Results (means of three experiments) are given as percentages of values recorded for fresh semen $(\square)$. Samples were stored aerobically, and hatched by shaking $(\varangle)$, or anaerobically $(\boldsymbol{Q})$ in sealed tubes.

the laying down of the outer layer. If so, these changes are unlikely to provide a chemical block to penetration of the spermatozoa, since the separated inner layer still retains sperm-binding and activating functions. Therefore, the role of the outer layer seems to be to act as a mechanical barrier to the further penetration of spermatozoa, as suggested by Howarth and Digby (1973). Other electophoretic studies have demonstrated major peptides of the perivitelline layer of different molecular masses: Kido and Doi (1988) reported peptides of $32 \mathrm{kDa}, 183 \mathrm{kDa}$ and $1000 \mathrm{kDa}$, while Howarth (1992) reported peptides of $33 \mathrm{kDa}, 54 \mathrm{kDa}$ and $200 \mathrm{kDa}$. However, both of these studies used non-reducing SDS-PAGE and Howarth (1992) also used inner perivitelline layers that had first been solubilized in $5 \mathrm{mmol}$ phosphate buffer $\mathrm{l}^{-1}$.

No significant difference was found between the inner perivitelline layers from follicular and laid eggs in assays of the interaction between the spermatozoa and this layer. Large standard deviations, where they occurred, were a result of variation in the source of inner perivitelline layer, from different eggs, and of semen, from different males. Spermatozoa 
quality varies between males (Wishart and Palmer, 1986) and recent work has shown that assay of the interaction between spermatozoa and the inner perivitelline layer can be used for predicting the fertilizing ability of semen from different males (L. Robertson et al., in press). Variation in the number of holes in the inner perivitelline layer, for a given concentration of spermatozoa, was found to be small within samples of this layer from the same egg. However, greater variability was found between samples of the inner perivitelline layer from different eggs. A similar situation has been documented in mammalian systems where human hemizona assays showed up to $14 \%$ variability in sperm binding capability in one zona pellucida but over $100 \%$ variation between different zonae (Franken et al., 1991). However, with the avian system it is possible to obtain many replicate pieces of the inner perivitelline layer from a single egg. Thus, up to twenty samples of spermatozoa can be compared using an 'experimental unit' of 20 samples of inner perivitelline layer from the same chicken egg.

Hydrolysis was found to have occurred within $2.5 \mathrm{~min}$ of incubation with only the size of the holes increasing with further incubation, as the proteolytic enzymes released after induction of the acrosome reaction continued to digest the layer. After $5 \mathrm{~min}$, the number of holes had not increased significantly but they were much clearer; therefore $5 \mathrm{~min}$ was chosen as the optimal incubation time for the assay. On prolonged incubation, the holes became so large that they tended to coalesce.

The frequency of holes in the inner perivitelline layer was found to increase linearly with the concentration of spermatozoa in the assay. Howarth (1992) reported a similar effect with inner perivitelline layer from freshly ovulated ova, but also found that at concentrations above $2 \times 10^{6}$ spermatozoa $\mathrm{ml}^{-1}$ this relationship was asymptotic. We found that the detection and counting of individual holes became inaccurate in samples exposed to high sperm concentrations for $5 \mathrm{~min}$ because, as for prolonged incubations, single holes began to coalesce. At lower sperm concentrations, the frequency of holes was more than that predicted by extrapolation of results with higher sperm concentrations (L. Robertson, unpublished data). Howarth (1992) also reported this phenomenon, which suggests a minimum threshold concentration of spermatozoa required for binding. It remains unclear whether this represents a synergistic relationship between spermatozoa or the necessity for a threshold concentration of some effector.

The major limiting factor in the development of methods for storing avian semen, whether liquid or cryopreserved, has been the lack of adequate in vitro tests for predicting the fertilizing ability of the semen and the variability and complexity of 'fertility trials' (Wishart, 1989). Although the results of current in vitro tests are highly correlated with those obtained using fresh semen (Wishart and Palmer, 1986; Chaudhuri and Wishart, 1988), the methods used assess only a single parameter, for example motility, metabolic activity or dye exclusion, and tend to overestimate the fertilizing ability of stored semen (Wishart, 1989).

Extensive fertility trials have shown that, following cryopreservation by the method used in this work, less than $2 \%$ of chicken spermatozoa retain their fertilizing ability (Wishart, 1985). However, most in vitro tests overestimate the fertilizing ability of cryopreserved chicken spermatozoa by showing that $30-40 \%$ retain functional and metabolic integrity after cryopreservation (Wishart, 1989). The ability to reduce INT, which has been shown to be a good predictor of the fertilizing ability of fresh spermatozoa from individual male chicken, also decreases to $30 \%$ following spermatozoa cryopreservation. In contrast, the spermatozoa-inner perivitelline layer interaction assay shows that the ability of cryopreserved spermatozoa to hydrolyse the inner perivitelline layer was reduced to $8.5 \%$. Cramer et al. (1994) also noted a reduction in fertilizing ability with cryopreserved chicken spermatozoa and suggested a link between this and a reduction in spermatozoa-egg binding. Their test system showed that, after cryopreservation, the number of spermatozoa that was capable of binding to immobilized proteins from the 'whole' inner perivitelline layer (i.e. both inner perivitelline layer and outer perivitelline layer) was reduced to $18 \%$. However, they also found that several species of mammalian spermatozoa bound to these proteins, whereas we have found ( $\mathrm{L}$. Robertson, unpublished results) that bull, mouse, rat or human spermatozoa did not hydrolyse the inner perivitelline layer. Thus, the system of Cramer et al. (1994) appears to be assessing a different parameter from the assay described here. In contrast to these findings with cryopreserved avian spermatozoa, human spermatozoa have a similar or even an increased ability to bind to the zona pellucida after cryopreservation (Gamzu et al., 1992).

After storage under aerobic or anaerobic conditions at $5^{\circ} \mathrm{C}$ for $24 \mathrm{~h}$, both the dye exclusion test and the tetrazolium dye reduction assay showed that at least $80 \%$ of the spermatozoa were viable and functionally intact. However, the in vitro spermatozoa-egg assay showed a vast reduction in the ability of spermatozoa to hydrolyse the inner perivitelline layer $(53 \%$ for aerobic and $91.5 \%$ for anaerobic storage), indicating that subtle changes occurred during storage that could not be detected by dye reduction or exclusion tests. Although aeration of chicken semen during liquid storage at low temperature has been shown to improve the maintenance of sperm fertilizing ability (Wishart, 1981), no good quantitative assessment of the effect of such storage on fertilizing ability has been made along the lines of that applied to cryopreserved chicken spermatozoa (Wishart, 1985). Our results for the interaction between spermatozoa and the inner perivitelline layer may therefore highlight the true nature of the effect of storage of chicken semen at $5^{\circ} \mathrm{C}$. For diluted turkey semen, where there is an absolute requirement for oxygen to maintain the concentration of ATP in spermatozoa (Wishart, 1982), no activity of spermatozoa towards the inner perivitelline layer could be found after $24 \mathrm{~h}$ storage under anaerobic conditions at $5^{\circ} \mathrm{C}$ (Wishart and Robertson, 1995).

It is clear that most in vitro tests of avian sperm 'quality' are limited in the parameters that they measure, compared with the many functions of spermatozoa required for successful fertilization after intravaginal insemination (see Bakst et al., 1994). It has been proposed that one major fault of these tests is that none assess characteristics of the sperm surface, which are clearly important for the migration of spermatozoa through the vagina (Steele and Wishart, 1992) and appear to be compromised during storage of liquid semen (Fulcher et al., 1988). Furthermore, none of the tests currently used assess the acrosomal damage of avian spermatozoa, which would Downloaded from Bioscientifica.com at 04/26/2023 10:07:00AM 
undoubtedly affect their fertilizing ability. The assay for the interaction between spermatozoa and inner perivitelline layer introduced in this paper requires that a range of functions, motility, binding to the inner perivitelline layer, induction of the acrosome reaction and hydrolysis of the inner perivitelline layer, should be performed, each of these in themselves requiring a complex interaction of sperm metabolic and regulatory parameters. Thus, the test is likely to be highly discriminatory against compromised spermatozoa. The fact that the test does not require high technology and is inexpensive and simple to perform should ensure its ready application to avian fertility systems.

The authors thank the BBSRC for a project grant to G. J. Wishart.

\section{References}

Bakst MR and Howarth B, Jr (1977) Hydrolysis of hens perivitelline layer by cock sperm in vitro. Biology of Reproduction 17 370-379

Bakst MR, Wishart GJ and Brillard J-P (1994) Oviducal sperm selection, transport and storage in poultry Poultry Science Reviews 5 117-143

Blum H, Beier $\mathbf{H}$ and Gross $\mathrm{HJ}$ (1987) Improved silver staining of plant proteins, RNA and DNA in polyacrylamide gels Electrophoresis 8 93-99

Bramwell RK and Howarth B (1992) Preferential attachment of cock spermatozoa to the perivitelline layer directly over the germinal disc of the hen's ovum Biology of Reproduction 47 1113-1117

Burrows WH and Quinn JP (1937) The collection of spermatozoa from the domestic fowl and turkey Poultry Science 16 19-24

Chaudhuri D and Wishart GJ (1988) Predicting the fertilising ability of avian semen: the development of an objective colourimetric method for assessing the metabolic activity of fowl spermatozoa British Poultry Science 29 $837-845$

Cramer PG, Barbato GF and Hammerstedt RH (1994) Sperm-egg binding assay assessing potential fertility of rooster sperm Biology of Reproduction 50 (Supplement 1) Abstract 293

Franken DR, Coddington CC, Burkman LJ, Oosthuizen WT, Oehinger SC, Kruger TF and Hodgen GD (1991) Defining the valid hemizona assay: accounting for binding variability within zonae pellucidae and within semen samples from fertile males Ferfility and Sterility 56 1156-1161

Fulcher KD, Beck CF and Cloud JG (1988) Changes in surface antigen quantity and distribution over time on avian sperm cells held at $4^{\circ} \mathrm{C}$ Biology of Reproduction 38 Abstract 81

Gamzu R, Yogev L, Yavetz H, Homonnai ZT, Hiss Y and Paz G (1992) Fresh and frozen-thawed human sperm bind in a similar pattern to the zona pellucida in the hemizona assay Fertility and Sterility 58 1254-1256

Haije U (1990) Evaluation and cryopreservation of fowl semen (Gallus domesticus) Doctoral Thesis University of Utrecht
Howarth B (1992) Carbohydrate involvement in sperm-egg interaction in the chicken Journal of Receptor Research 12 255-265

Howarth B and Digby ST (1973) Evidence for the penetration of the hen's ovum by a trypsin-like acrosomal enzyme Journal of Reproduction and Fertility 33 $123-125$

Kido S and Doi Y (1988) Separation and properties of the inner and outer layers of the vitelline membrane of hen's eggs Poultry Science 67 476-486

Koyanagi F, Masuda H and Nishiyama H (1988) Acrosome reaction of cock spermatozoa through the vitelline membrane in the domestic fowl Cell and Tissue Research 188 497-508

Laemmli UK (1970) Cleavage of structural proteins during the assembly of the head of bacteriophage T4 Nature 227 668-680

Lake PE and Ravie O (1981) An attempt to improve the fertility of stored fowl semen with certain additives in a basic diluent Reproduction, Nutrition and Development 21 1077-1084

Lake PE and Stewart JM (1987) Preservation of fowl semen in liquid nitrogen an improved method British Poultry Science 22 71-77

Longo FJ (1987) In Fertilization pp 46-57 Chapman and Hall, Cambridge

Montgomery DE (1991) Design and Analysis of Experiments pp 439-469 John Wiley and Sons Inc, New York

Okamura $\mathrm{F}$ and Nishiyama $\mathrm{H}$ (1978) The passage of spermatozoa through the vitelline membrane in the domestic fowl (Gallus gallus) Cell and Tissue Research 188 497-508

Perry MM (1987) Nuclear events from fertilisation to the early cleavage stages in the domestic fowl (Gallus domesticus) Journal of Anatomy 150 99-109

Robertson L, Wilson YI, Lindsay C and Wishart GJ Evaluation of semen from individual male domestic fowl by assessment of sperm:perivitelline interaction in vitro and in vivo. British Poultry Science, (in press)

Steele MG and Wishart GJ (1992) A vaginal sperm-selection mechanism recognises sperm surface proteins. In Proceedings of the 12th International Congress on Animal Reproduction 1593-1595 The Hague, The Netherlands

Steele MG, Meldrum W, Brillard JP and Wishart GJ (1994) The interaction of avian spermatozoa with the perivitelline layer in vitro and in vivo. Journal of Reproduction and Fertility 101 599-603

Wishart GJ (1981) The effect of continuous aeration on the fertilising ability of poultry semen at $5^{\circ} \mathrm{C}$ British Poultry Science $22445-450$

Wishart GJ (1982) Maintenance of ATP concentrations in and fertilising ability of fowl and turkey spermatozoa in vitro. Journal of Reproduction and Fertility $66457-462$

Wishart GJ (1985) Quantitation of the fertilizing ability of fresh compared with frozen and thawed fowl spermatozoa British Poultry Science 26 375-380

Wishart GJ (1989) Physiological changes in fowl and turkey spermatozoa during in vitro storage British Poultry Science 30 443-454

Wishart GJ (1995) Cryopreservation of avian spermatozoa. In Cryopreservation and Freeze-Drying Protocols. Methods in Molecular Biology (Vol. 38) pp 167-177 Eds JG Day and MR McLellan. Humana Press, Totowa, NJ

Wishart GJ and Palmer FH (1986) Correlation of the fertilizing ability of semen from individual male fowl with sperm motility and ATP content British Poultry Science 27 97-102

Wishart GJ and Robertson L (1995) Sperm:egg interaction in turkeys in vitro and in vivo. Turkeys 43 19-22 